\title{
A study on medical Experts input in crime scene investigations (CSI); Is there room for improvement? A preliminary study for a National Audit
}

PAS Edirisinghe ${ }^{1}{ }^{*}$ IDG Kitulwatte ${ }^{1}$, WDJK Amarasena ${ }^{1}$, IKST Wellagiriya ${ }^{1}$, N.V Lawrence ${ }^{2}$

${ }^{1}$ Department of Forensic Medicine, Faculty of Medicine, University of Kelaniya

${ }^{2}$ Police SOCO unit, Sapugaskenda- Kelaniya Police Division.

*Corresponding author: Tel: 0094-11-2958219. E-mail address: anuruddhi@hotmail.com

\begin{abstract}
Introduction: CSI is an investigation into a 'suspicious incident' where there is an alleged criminality. Although the primary investigator is the police, CSI is a team effort and services of various experts are obtained to collect evidence in its pristine state.
\end{abstract}

Objective: To determine the percentage and type of crime scene investigations where medical officers input was obtained and to evaluate the type of contribution by medical experts.

Method: A retrospective descriptive study was carried on all CSI of alleged murder cases that Police SOCO Unit Sapugaskanda attended from $1^{\text {st }}$ of January 2008 to $31^{\text {st }}$ August 2009. An interviewer administered questionnaire was designed where answering was based on data from case notes, personal experiences of the SOCO officers and one opinion question. The questionnaire was first assessed for face and content validity in 10 cases.

Results: Out of 78 CSI conducted 3 incidents had multiple deaths ( $n-16$ \& 4) where two were bomb explosions. $23 \%, 21 \% \& 17 \%$ were from sharp force trauma, explosions and firearms respectively. In $13 \%$ of cases causative factor was not obvious to SOCO officers. Half of the cases (n-39) were informed during morning hours and police records stated $98 \%$ were attended within 30 minutes. JMO was called for 11 incidents varying from explosion(1), asphyxia(3), sharp force(2), burn(1), skeletal remains(1) to not known(3). The reason for calling was to get assistance in interpreting injuries and advice on further investigation in 67\% of cases. Question on SOCO officer's opinion on expert opinion of JMO resulted $100 \%$ satisfaction. The practice of producing CSI photographs to the JMO was not conducted in a uniform manner.

Conclusion: CSIs that were attended by JMOs resulted in satisfactory address of issues. If the practice of viewing of digital scene visit photos prior or after autopsy is regularized with routine reviews, quality of medical expert input will increase.

Keywords: Crime Scene Investigations (CSI), Scene of Crime Officers (SOCO), medical experts, expert opinion

\section{Introduction}

Crime Scene Investigation popularly known as CSI or investigation into a scene of crime is actually an investigation into a 'suspicious incident' where there is an alleged criminality.
Although the main investigator is the police it is well known that CSI is a team effort where services of various experts are obtained to collect evidence in its pristine state at any future trial [1]. Presence of a medical expert in a crime scene investigation will help in 
collection of evidence from the deceased, reconstruction of final events leading to death, including the injury interpretation, time since death and likely cause of death[1][2].

The concept of Scene of Crime Officer (SOCO) units taking in charge of an alleged crime scene came to routine practices of police during 20062007 after a training programme introduced to Sri Lanka Police with help of Swedish experts. Well equipped SOCO units with trained police officers were established in various police divisions. The first Police SOCO unit for Sri Lanka was established for Kelaniya Police Division at Sapugaskanda Police premises in July 2006. [3] Sapugaskanda SOCO unit look after an area of $70 \%$ of Gampaha District with 1387 $\mathrm{Km}^{2}$ and a population density of 1539 persons per $\mathrm{Km}^{2}$ of [4] comprising of 12 police stations. Annually SOCO unit handle about 300 cases of investigations of crime scenes which includes 50-75 alleged murder cases. [5]

CSI in Sri Lanka has taken a leap after the development of SOCO units. Recording of events with digital photography, calling up of experts into CSIs, collection and transportation of forensic evidences are happening in more methodically. No study has been done regarding the evaluation of the quality of the work and the contribution of experts especially of medical experts at the scene visits. Therefore, studying this matter in depth will enable to recommend some good practices and working norms for quality evidences in future trials.

\section{Objective}

To determine the percentage of crime scene investigations that a medical officer attend or medical experts consulted with the scene visit findings or retrospective scene visit investigations done and to evaluate the type of contribution of the medial expert given in the crime scene investigations.

\section{Method}

A retrospective descriptive study was carried on all CSI of alleged murder cases that Police SOCO Unit Sapugaskanda attended from $1^{\text {st }}$ of January 2008 to $31^{\text {st }}$ August 2009. An interviewer administered questionnaire was designed where answering was based on data from case notes, personal experiences of the SOCO officers and their opinions. The questionnaire $(\mathrm{n}-25)$ included few demographic data followed by 7 questions on attendance to crime scene. Data pertaining to these questions were taken from police log books, case records and by recalling. Next set of questions were on other expert inputs and evidence collection. Finally the opinion of the police officers regarding the usefulness of medical expert's input was questioned. A pilot study on 10 cases was carried out initially to assess the questionnaire for face and content validity. The data collected were entered into $\mathrm{XL}$ data sheets and analysed with Statistical package of Social Sciences version 14.

\section{Results}

During the study period Sapugaskanda SOCO unit has conducted over $300 \mathrm{CSI}$ where 78 incidents were alleged homicides. 3 incidents had multiple deaths, with 16, 4 and 2 deaths respectively. Thus, the number of total deaths were 97. Multiple deaths were from two incidents of suicide bomb explosions and 1 incident of two decomposed bodies recovered from a marshy land. Sharp force trauma accounted for $(28 \%)$ of the alleged incidents followed by firearms (21\%). In $15 \%$ of cases causative factor was not obvious to SOCO officers. (Figure 1). 


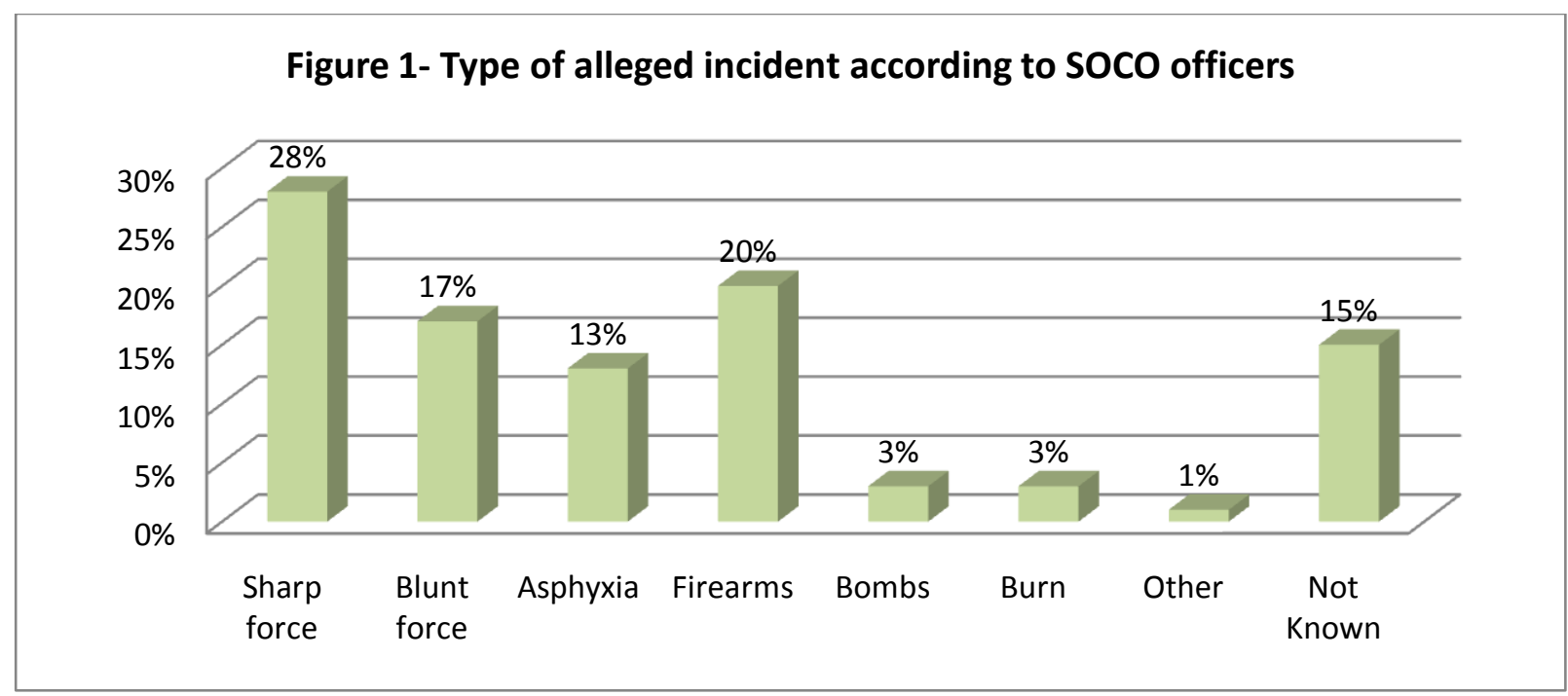

\section{Demographic details}

Nearly half of the victims ( $n-44)$ were in their prime youth (21-40 year) while in $17 \%$ of cases age was not known. Majority were males with male to female ratio of $7: 1$. The highest number of deaths during the study period was recorded from Weliweriya police division due to a suicide bomb explosion. If this incident was not there the lowest number of deaths would be from Weliweriya, a rural cultivation area. (Figure 2)

\section{The Incident and response of the SOCO unit}

Majority (51\%) were informed by the public during morning hours while late night informing was only $8 \%$. According to the records available either the local police or the patrolling police vehicle has gone to the incident within $30 \mathrm{~min}$ in all the cases except two incidents (98\%). However, the SOCO units have gone to the all the scenes within 30 minutes of informing them.

Out of 78 incidents 74 was attended by the Magistrate while 3 were attended by Inquirer into Sudden Deaths. In one case there was no clear record available regarding the inquiring officer. The analysis of the time of the magistrate's arrival at the scene resulted that only one eighths $(10 \%)$ of incidents were visited within 2 hours of informing and 15\% of incidents were visited after 12 hours. (Figure 3) In $51 \%$ of incidents the deceased was found at the scene while the rest were brought to the hospital.

\section{Judicial Medical Officer and CSI}

JMO was called for 11 incidents(14\%) varying from explosion(1), asphyxia(3), sharp force(2), burn(1), skeletal remains(1) to not known(3). The reasons for calling doctor varied but in all the incidents they stated it was to get assistance for proper investigation. (Figure 4) Out of 11 incidents the body/s of the deceased was/were not found in the scene in 3 cases. (1 asphyxia, 1 bomb, 1 unknown). According to memory of the investigating officer, the initiation to inform the JMO was done by SOCO unit in all cases and the Magistrate complied with it.

Out of 11 incidents JMO visited, eight were attended by JMO unit Ragama while the bomb blast involving 16 casualties was attended by JMO Gampaha. Institute of Legal Medicine and Toxicology Colombo attended 2 incidents. Out of 11, two incidents were attended by Consultants while the rest were by grade medical officers. In 9 incidents JMO arrived at the scene before the Magistrate. 
Figure 2- Number of homicides per police area

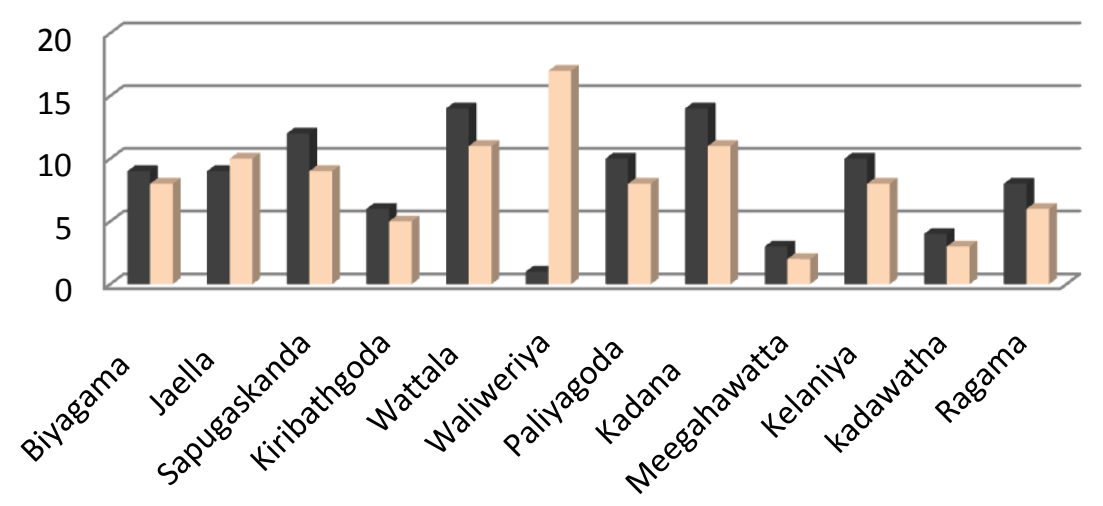

With out Bomb Blast With Bomb Blast

Figure 3- Time of the Magistrate attended the scene from time of informing

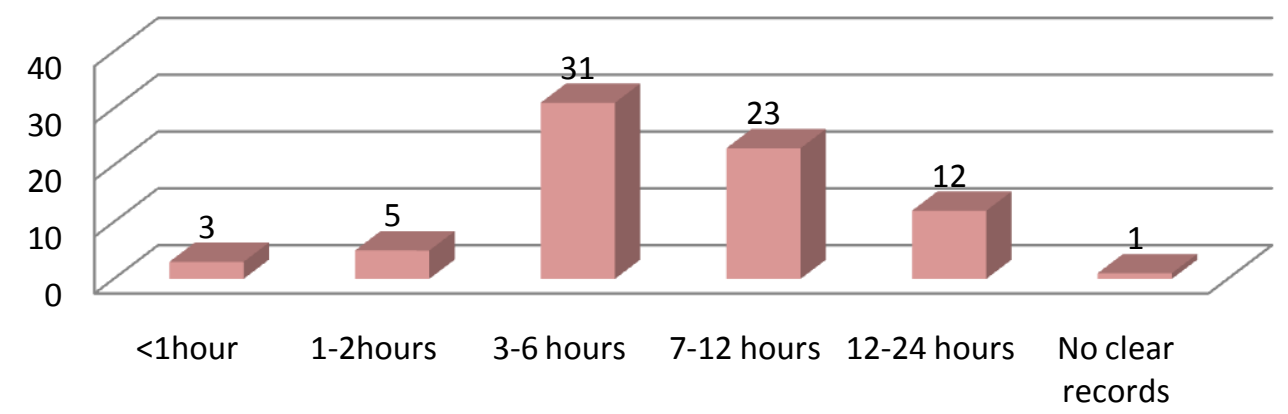

Figure 4- The reason for calling doctor to the Scene

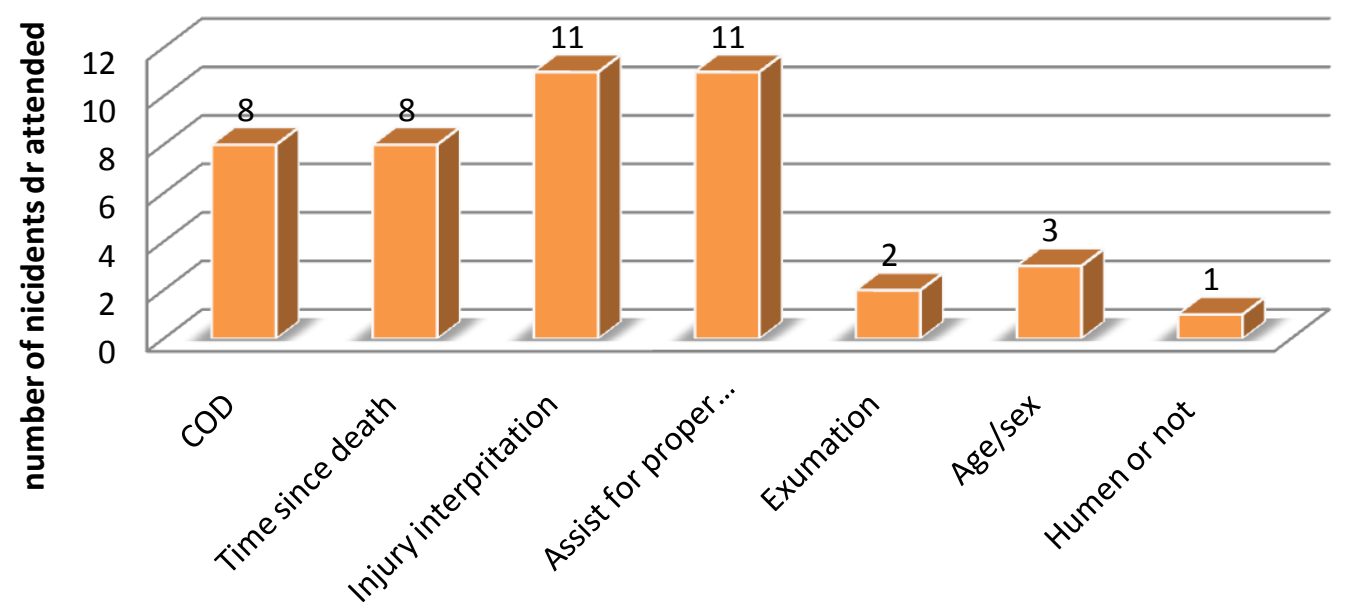


The main reason to call the JMO was to get an opinion on issues regarding interpretation of injuries and type of the weapon, at the scene. (Table 1) Although a weapon was recovered in 21 cases only in 15 cases it was produced at the autopsy for an opinion.

Opinion on usefulness of JMO's input at the scene resulted $100 \%$ satisfaction and the medical opinion stated in the preliminary cause of death certificate adequately answered the issues which the JMO was called.

The practice of retrospective examination of the scene with a set of photographs and sketches by the medical expert is a common practice in other countries. In our study 58 cases had written oral evidence, digital photos and a sketch while the two explosions had video recording too. In 18 cases there were no photographic evidences (digital/or hard copies) but had a sketch and oral evidence. According to the SOCO officers they do not produce photographic evidences- digital or hard copies

\begin{tabular}{|c|c|c|c|c|c|c|c|c|c|c|c|}
\hline \multirow{3}{*}{ Reason for calling JMO } & \multicolumn{10}{|c|}{ Incident attended with its type } & \multirow[t]{3}{*}{ Total } \\
\hline & 12 & 3 & 4 & 5 & 6 & 7 & 8 & 9 & 10 & 11 & \\
\hline & E & A & A & SF & SF & BU & SK & NK & NK & NK & \\
\hline Issues regarding the cause of death & & Y & Y & Y & & Y & Y & Y & Y & Y & 8 \\
\hline Issues regarding the time since death & & Y & Y & Y & & Y & Y & Y & Y & Y & 8 \\
\hline $\begin{array}{l}\text { Issues regarding the interpretation of the } \\
\text { injuries }\end{array}$ & Y & $\mathrm{Y}$ & Y & Y & Y & Y & Y & Y & $\mathrm{Y}$ & $\mathrm{Y}$ & 11 \\
\hline $\begin{array}{l}\text { To get advice for further forensic } \\
\text { investigations - } \\
\text { Type of weapon used }\end{array}$ & Y & Y & Y & Y & Y & $\mathrm{Y}$ & Y & Y & $\mathrm{Y}$ & $\mathrm{Y}$ & 11 \\
\hline $\begin{array}{l}\text { Other investigations- toxicology, bio- } \\
\text { chemistry, DNA, entomology }\end{array}$ & & & & & & & & & & & \\
\hline
\end{tabular}

\section{Any other reason \\ For Exhumation \\ Age sex \\ Human or not}

Total (reasons to call)

Table 1- Reasons for calling a JMO to the Scene (E-Explosion A-asphyxia, SF- Sharp force, B-Burns SK-Skeletal remains, NK- causative factor not obvious)

\section{Discussion}

The necessity of the presence of various experts input at a crime Scene investigation has long as a routine practice to the JMO before or after the autopsy in all cases. It was only on request.

According to SOCO officers, practice of obtaining photographs during an autopsy examination varied from one expert to the other. Out of 97 autopsy examinations autopsy photographs were available in 63 individuals with SOCO unit.

\section{Other experts \& CSI}

CSI is a team effort, and many experts are called to the scene to assist investigating officers. Out of 78 incidents 34 cases were attended by fingerprint experts, while two cases were attended by bomb disposal squad and explosive experts from the Government Analyst Department. In one case police dogs were brought to the scene. 
crime scene managers and experts are called to a crime scene at various stages in the investigation, and presence of a medical expert may be due to various reasons ranging from resuscitation of the living, pronouncing life extinct to forensic expert opinion. [1] Although the former two can be achieved by a general practitioner the latter has to be done by a forensic pathologist.

This study on the CSI conducted by the SOCO unit Kelaniya showed the typical trends of homicidal pattern observed previously was still continuing [9] but quality CSI is yet to improve. The study revealed though police and the SOCO unit reach the place of incident early (half an hour of receiving the information what ever the time of the day) the time of the arrival of the magistrate had unhealthy trends. This has been shown previously by Chandrasiri suggesting the need to change section 370 of Code of Criminal Procedure Act of Sri Lanka. [10] The law related to CSI in Sri Lanka state that the Inquirer into sudden death or the Magistrate is the only person empowered to go to the scene, record injuries and arrive at an apparent cause of death. [11] Since many of the inquirers and magistrates are lay people who have no medical or scientific knowledge and training on crime scene investigations loss of valuable evidence, tampering of evidences are expected to occur. One of the positive aspects of the arrival times of the medical expert in this study was that in majority of cases (9 out of 11) the medical officer arrived before the Magistrate.

Our main objective of this study is to determine the percentage of CSIs medical officer/s attend or medical experts consulted resulted $14 \%$ indicating that there is room for improvement. The area that can be easily corrected is the availability of digital photographs. There was no record to indicate that these were shown or copies were sent to the forensic pathologist before or after autopsy. The SOCO officers free comments clearly show that the need of early well planned operational procedures regarding
CSI are needed if we are to have a more scientific input in the crime scene.

The analysis of the results of the question on why a medical expert was called to the scene clearly indicated that the "SOCO" officers were still holding the archaic view that a medical expert can only help in identifying the issues of cause of death and the weapon. Time since death, and the issues associated with early postmortem interval were ignored where scientific investigations can be done to certain accuracy. Out of the scenes visited by the doctor many cases were decomposed bodies and any opinion based on crime scene investigation is difficult to give without further examination.

Study also revealed that the attendance of other scientific experts at CSI is mainly limited to finger print experts while contribution of the other scientific experts was minimal. Thus being the only expert present at the scene with a scientific background the forensic pathologist (JMO) may have to play multiple roles at obtaining and preserving evidence (serology, DNA, entomology). This also makes crucial the early attendance of crime scenes by the Forensic Pathologist(JMO).

The satisfaction of the SOCO officers, resulting $100 \%$ on expert's input to the crime scene indicated that the officer's main target was at the cause of the death and the offending weapon. They were not much concerned about the issues on time since death or reconstruction of the event. This highlighted the need of development of more scientific training in scene of crime investigations.

\section{Conclusions}

This study showed that there were many areas that need improvement especially on operational procedures where medical expert input can change many things. The underutilization of medical expert in the era of technology where expert opinions can be taken without much cost was seen. Although CSIs that 
were attended by Forensic Pathologists resulted in satisfactory address of 'issues', forensic issues benefited from an early death scene investigation were never considered or thought of. We suggest initiation of regular education programs to the "SOCO" officers with special attention paid on the goals of death scene investigations. The practice of viewing of digital scene visit photos prior or after autopsy if regularized by issue of best practice guidelines or operational procedures quality of CSI can be improved.

\section{References:}

1. A. Busuttil, Scenes of crime- the Pathologists and others, in Forensic Medicine Clinical and Pathological Aspects Eds. J. Payne James, A Bussuttil, W Smock, Greenwitch London, 2003; 49-56

2. Vanezis P, Busuttil A., Suspicious death scene investigation. Arnold London. 1996

3. Personal Communication: Mr. Asoka Wijetilleke, DIG International affairs, Inspection \& Review, Research \& Planning Police Head quarters

4. Department of Census and Statistics of Sri Lankahttp://www.statistics.gov.lk/Pocket\%20Boo k\%202008(English)/chap02.pdf Web site contacted on 20.10.2009

5. Personal Communication SOCO unit, Sapugaskanda
6. Gross $\mathrm{H}$ Criminal investigation 1892

7. Horswell J, The Practice of Crime Scene Investigation CRC Press. New York 2004

8. Fisher BAJ Techniques of Crime Scene Investigation, $7^{\text {th }}$ Edition. CRC Press. New York 2006

9. Edirisinghe PAS, Kitulwatte IDG. Extreme violence- Homicide; an analysis of 265 case from the Office of JMO Colombo and Ragama- A study from Sri Lanka. Legal Medicine, 20009;11:S563-565

10. Chandrasiri N. Examination of a scene of crime; do we need to amend section 370 of the Code of Criminal Procedure Act of Sri Lanka? Ceylon Med J. 2001;46(2):61-3.

11. Code of Criminal Procedure. Act No. 15 of 1979, p 146.

\section{Contribution of authors}

Design to the study - PASE, IDGK, WDJKA, IKSTW, NVL

Supervision to the study- PASE

Analysis of the data- WDJKA, IKSTW, PASE

Interpretation of the results- PASE, IDGK

Writing the manuscript -PASE

Revising the manuscript-IDGK, PASE 